\title{
Percalços da TV pública: \\ o caso da TV Cultura
}

Laurindo Leal Filho

T ELEVISÃO NO Brasil sempre foi sinônimo de empreendimento comercial. Desde a instalação da Tupi em São Paulo, "a pioneira da América Latina", até hoje, TV e comércio se imbricam de tal forma que abrem espaço apenas para os dividendos políticos recebidos por seus controladores. Graças às concessões obtidas do governo, esses grupos empresariais têm acesso privilegiado ao poder, alcançando simultaneamente, e com sucesso, seus objetivos econômicos e políticos.

Diferentemente da Europa, onde a televisão se consolidou como herdeira do teatro, ou dos Estados Unidos, onde as origens estavam no cinema, no Brasil a TV cresceu à imagem e semelhança do rádio. Herdou programas, artistas, jornalistas e - acima de tudo - as estruturas empresariais. Foi uma continuidade suave que para o público passou quase despercebida. Os empresários de rádio tornaram-se empresários de televisão e o modelo público ficou fora do imaginário popular.

Dessa forma, tornou-se difícil construir uma consciência crítica em relação ao modelo oferecido. As possibilidades comparativas simplesmente inexistiam. O segundo governo Vargas ainda que tentou, ao outorgar uma concessão de TV à Rádio Nacional do Rio de Janeiro, sem, no entanto, colocá-la no ar. O que permitiu ao presidente Kubitschek, sob forte pressão, transferi-la para as Organizações Globo.

Sobraram tentativas regionais, como a da criação de uma TV educativa pela prefeitura do então Distrito Federal, no Rio, no início dos anos 1950. Ou, depois, da TV Universitária do Recife. E, a mais ampla e consistente de todas, a da TV Cultura em São Paulo, impulsionada pelo governo do Estado que a adquiriu dos Diários e Emissoras Associados. Os mesmos que fundaram a Tupi e que forçaram JK a não levar à frente o projeto varguista de uma televisão pública nacional.

São meandros da história da televisão brasileira, carente até hoje de uma bibliografia mais ampla. Estamos ainda longe de compêndios como aquele produzido pelo historiador Asa Briggs que, em quatro portentosos volumes, traça um painel consistente da história da radiodifusão britânica. Por aqui, vamos por partes. A universidade produz alguns trabalhos que viram livros, pesquisadores independentes se dedicam a uma ou outra emissora, e algumas empresas de comunicação contam a suas histórias oficiais. E ficamos por aí.

Assim, livros novos reunindo e organizando aspectos ainda que parciais da história de nossa TV são sempre bemvindos. É o caso de Uma história da TV Cultura, assinado por Jorge da Cunha Lima, presidente do Conselho Curador da Fundação Padre Anchieta, entidade mantenedora das emissoras públicas de rádio e de televisão vinculadas ao governo do Estado de São Paulo.

Participante ativo de mais de dois terços da vida da Fundação, Cunha Lima assumiu tarefa difícil: contar uma histó- 




Gravação do programa Roda Viva, da TV Cultura, em São Paulo (SP).

ria no duplo papel de narrador e personagem. Vale-se especialmente de depoimentos de ex-funcionários da emissora e tenta costurá-los com uma visão pessoal dos fatos marcantes da vida dessa que é - sem dúvida - a mais exitosa experiência de TV pública já realizada no Brasil. Êxito obtido apesar de todos os percalços e dificuldades mostrados no livro.

Constituída como fundação de direito privado, a Fundação Padre Anchieta deveria manter em relação ao governo estadual rígida independência, administrativa e financeira. O que não ocorreu. Fica da leitura a nítida sensação de que, enquanto alguns profissionais competentes buscavam prestar à sociedade um eficiente serviço público de radiodifusão, todos os governos - uns mais outros menos - viam a TV e a Rádio Cultura como canais de expansão de seus projetos político-eleitorais.

Nesse sentido dois momentos são emblemáticos: os governos Maluf e Al- ckmin. Em ambos, tenta-se aproximar a TV Cultura dos padrões das emissoras comerciais com a expectativa de que ela ganhe audiência, ao mesmo tempo que se investe na ampliação das áreas cobertas por seu sinal. O livro não conta, mas durante a gestão Maluf chegou-se a cogitar a contratação de apresentadores como Chacrinha e Hebe Camargo. O livro mostra, porém, como o governo Alckmin investiu num modelo de programação típico das TV comerciais com a contratação, por exemplo, de Silvia Poppovic e o seu programa de entrevistas. Mais ousados ainda que Maluf, os gestores dessa época tudo fizeram para que a Cultura assumisse a liderança de uma rede nacional de emissoras públicas, capaz de levar as realizações do governo paulista a todo o Brasil.

Sintomático é o espaço dado pelo autor às lutas políticas travadas pelo controle da emissora, fato que só reforça a tese da existência de uma incompreensão 


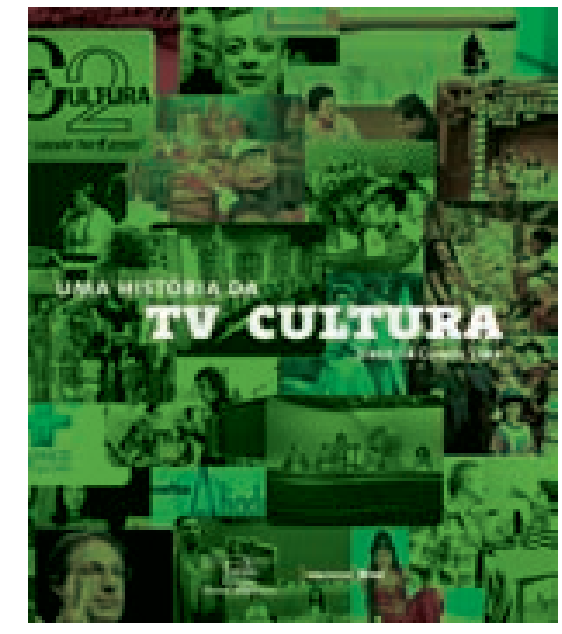

CUNHA LIMA, Jorge da. Uma história da TV Cultura. São Paulo: Imesp, 2009. 344p.

crônica dos governantes em torno do papel de uma emissora pública. Curiosos são os relatos dos momentos de tensão entre o Conselho Curador e os diferentes governos estaduais. Como da tentativa do sucessor do governador Maluf, José Maria Marin, de acabar com a independência institucional da Fundação. Na prática, essa independência praticamente inexistiu durante todo esse governo. As intervenções do governador nas emissoras de rádio e TV eram quase diárias. (Assim como o autor do livro, também fui personagem de parte dessa história. Cheguei, como redator do telejornalismo, a ter que editar e levar ao ar uma "reportagem" sobre a festa de aniversário do prefeito de São Paulo, Reinaldo de Barros, indicado por Maluf.)

Ao sair do governo para se candidatar a deputado federal, Maluf deixou ao seu sucessor a missão de oficializar essa prática intervencionista, mudando arbitrariamente a legislação numa tentativa de retirar o caráter público da instituição, medida derrubada na justiça, como conta o livro. A lamentar a ausência, no texto, de referências ao trabalho do curador de Fundações à época, Carlos Francisco Bandeira Lins, importante na luta pela manutenção da independência, ainda que relativa, da Fundação Padre Anchieta.

Outro momento de tensão relatado no livro trata da tentativa frustrada do autor de conquistar um quarto mandato de presidente da Fundação. Cunha Lima não esconde o seu campo político. Ao ser eleito pela primeira vez, diz que "era claramente vinculado ao grupo e ao pensamento do ex-governador Franco Montoro". Do qual fazia parte igualmente o governador que o acompanharia nas duas primeiras gestões: Mário Covas. $\mathrm{Na}$ terceira, conviveu com Geraldo Alckmin, do mesmo partido, mas alinhado a outra corrente, e que pretendia impor, na eleição seguinte, um nome de sua confiança para a presidência da Fundação.

Deu-se aí uma das mais encarniçadas batalhas pelo poder na instituição. Depois de nove anos à sua frente, Cunha Lima conseguiu moldar um Conselho a seu gosto, o que lhe garantiria votação tranquila para um novo mandato. O governo corria sério risco de derrota que, se consumada, poderia levar a Cultura à bancarrota, diante de uma provável represália oficial. A saída, contada com a devida sutileza pelo autor e personagem, foi aceitar o nome imposto pelo governo, mas tendo como contrapartida a sua efetivação na presidência do Conselho Curador, cargo agora devidamente remunerado.

Esse episódio conduz a uma pergunta cuja resposta o livro não dá: como são feitas as indicações dos nomes para o Conselho Curador? A força demonstrada pelo autor para enfrentar e impor 
condições ao governo do Estado revela um respaldo no Conselho cuja obtenção $\mathrm{o}$ livro não explica. $\mathrm{O}$ que leva à conclusão de que a generosa ideia de um órgão autônomo, capaz de expressar a vontade popular em relação às suas emissoras de rádio e $\mathrm{TV}$, sucumbiu à captura efetivada por um grupo político quase homogêneo.

Se, de um lado, o autor não conta como se constitui essa parte do poder na Fundação, de outro, é caudaloso em autoelogios e na defesa das suas três gestões diante das críticas sofridas, particularmente por meio da imprensa. Pena que não dê ao leitor a possibilidade de conhecê-las. Trata-as superficialmente e atribui a uma delas, por exemplo, "efeitos terríveis" para a instituição.

Reclama que a reportagem afugentou possíveis anunciantes, dando de barato que a publicidade já era um componente fundamental para o orçamento da TV pública. Em uma de suas gestões, foi aberta a porta para a propaganda, ainda que discreta, denominada "institucional". Porta que seu sucessor escancarou igualando a TV Cultura ao ritmo das emissoras comerciais e à consequente $\mathrm{e}$ inevitável subordinação da produção de conteúdo ao marketing.

Sobre o fato - já posterior às gestões do autor -, o livro abre espaço para depoimentos críticos como o da jornalista Bia Abramo. Diz ela sobre a propaganda:

Acho que muda a credibilidade mesmo. Acho que começa a cercear as possibilidades. Ainda não tenho observado isso do ponto de vista editorial, mas é o caminho: você começa a ter que responder, chega uma hora que você está no mercado, não tem mistério, você tem que responder ao mercado.
Aqui não há sutileza. O autor diz literalmente que "pretendeu-se aumentar a audiência - fator fundamental para sustentar a cota de anunciantes - procurando atrair para a TV Cultura o público afeito à TV comercial". Um trabalho realizado pelo seu sucessor, já na fase Alckmin. E, claro, abrindo espaços mais amplos para o proselitismo político com a volta ao ar, por exemplo, do programa Opinião Nacional, apresentado por um ex-secretário de Comunicação do governo Mário Covas, mencionado no livro, guindado igualmente a comentarista político da emissora. Além da tentativa, abortada na véspera, de levar ao ar um programa de entrevistas comandado por um secretário estadual e que teria como convidada inaugural ninguém menos do que a primeira dama do Estado.

E assim a TV pública, definida por sua equidistância em relação aos poderes político e comercial, subordina-se nesta última fase de forma mais aberta a interesses publicitários e partidários. De pública, transforma-se em estatalcomercial. O livro não diz nada disso de forma explícita, mas os dados nele reunidos permitem ao leitor atento chegar a essa conclusão. Para esse tipo de leitor, o livro é elucidativo.

Apesar dos descompassos com os princípios da radiodifusão pública, consagrados internacionalmente, a TV Cultura tornou-se referência de qualidade para grande parte da população paulista. Basta sair às ruas e perguntar o que as pessoas consideram uma programação de qualidade. Com certeza, a maioria apontará a da Cultura, mesmo que a vejam pouco. No entanto, em algum momento de suas vidas viram nela algo marcante, superior a tudo que é produzido pelas emissoras comerciais. 


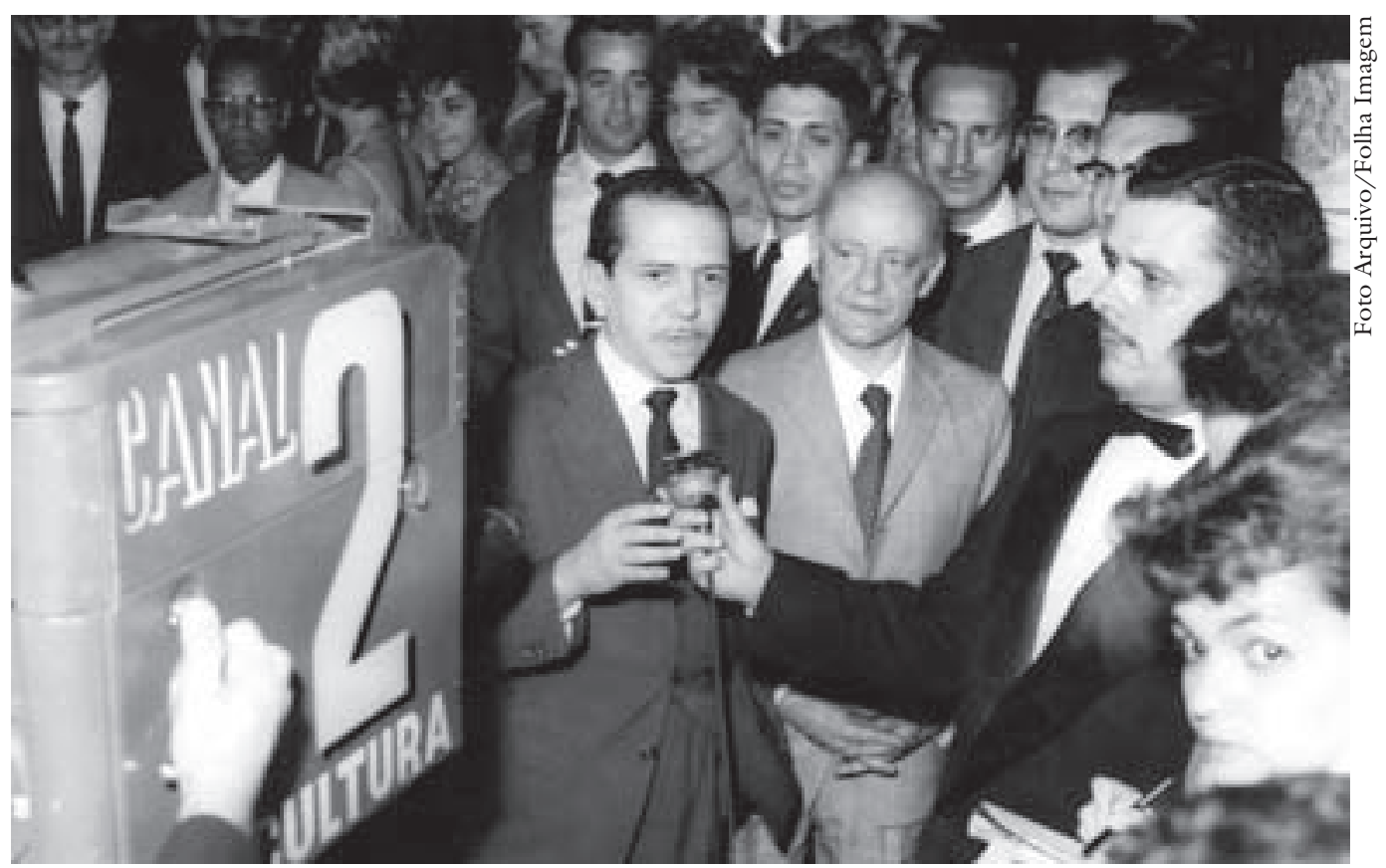

Lançamento do Canal 2, no dia 20 de setembro de 1960, em São Paulo (SP).

Nesse sentido, o livro é pródigo em exemplos fartamente ilustrados com fotos históricas. Lá está a faixa de programação infantil que, no início dos anos 1990, conquistou números de audiência inéditos para emissora, jamais alcançados outra vez. São programas que podem ser considerados clássicos da televisão brasileira, como Rá-Tim-Bum, X-Tudo, Glub-Glub e Mundo da Lua. Além do premiado Confissões de adolescente, para os maiorzinhos.

Personagens do Vox Populi, onde quem perguntava era o povo, são lembrados, como o líder sindical Luiz Inácio Lula da Silva, entrevistado em 1978. E depois o mesmo Lula no Roda Viva, que levou para os estúdios pessoas como Antonio Carlos Jobim, Pedro Almodóvar e Luis Carlos Prestes. Menção importante é feita também a Fernando Faro e seu Ensaio, por onde passaram, entre outros, Nelson Gonçalves, Chico Buarque, Dorival Caymmi, Lupicínio Rodrigues, Tim Maia e Elis Regina. Um programa que é, sem dúvida, o mais importante registro da música popular brasileira do século XX.

Por tudo isso e por muito mais, graças aos seus jornalistas, artistas, produtores, diretores e funcionários de todos os escalões, a Cultura tornou-se imprescindível para a sociedade paulista. O material organizado e publicado por Jorge da Cunha Lima testemunha essa história. Infelizmente, muito mais poderia ter sido feito em favor da sociedade, não fosse a mesquinha luta pelo poder que ocupa na vida da Cultura um espaço exagerado, refletido nas longas páginas a ela dedicadas pelo livro.

Laurindo Leal Filho é sociólogo, jornalista e professor do Departamento de Jornalismo e Editoração da Escola de Comunicações e Artes da USP. É autor dos livros Atrás das câmeras, relações entre Estado, cultura e televisão, sobre a TV Cultura de São Paulo. @- laloleal@uol.com.br 